\title{
Podocalyxin Is a Marker of Poor Prognosis in Pancreatic Ductal Adenocarcinom
}

\section{Saukkonen, Kapo}

2015-06-08

Saukkonen , K, Hagström , J , Mustonen , H , Juuti , A , Nordling , S , Fermer , C , Nilsson , O , Seppanen , H \& Haglund, C 2015 , ' Podocalyxin Is a Marker of Poor Prognosis in

Pancreatic Ductal Adenocarcinoma ', PLoS One , vol. 10 , no. 6 , 0129012 . https://doi.org/10.1371/journal.pone.012

http://hdl.handle.net/10138/160376

https://doi.org/10.1371/journal.pone.0129012

cc_by

publishedVersion

Downloaded from Helda, University of Helsinki institutional repository.

This is an electronic reprint of the original article.

This reprint may differ from the original in pagination and typographic detail.

Please cite the original version. 


\title{
Podocalyxin Is a Marker of Poor Prognosis in Pancreatic Ductal Adenocarcinoma
}

\author{
Kapo Saukkonen ${ }^{1,2 *}$, Jaana Hagström ${ }^{2,3}$, Harri Mustonen ${ }^{1}$, Anne Juuti ${ }^{1}$, Stig Nordling ${ }^{3}$, \\ Christian Fermér ${ }^{4}$, Olle Nilsson ${ }^{5}$, Hanna Seppänen ${ }^{1}$, Caj Haglund ${ }^{1,2}$ \\ 1 Department of Surgery, University of Helsinki and Helsinki University Hospital, P.O. Box 440, FIN-00029 \\ HUS, Helsinki, Finland, 2 Research Programs Unit, Translational Cancer Biology, University of Helsinki, \\ P.O. Box 63, FIN-00014 University of Helsinki, Helsinki, Finland, 3 Department of Pathology, Haartman \\ Institute and HUSLAB, University of Helsinki and Helsinki University Hospital, Helsinki, FIN-00014 University \\ of Helsinki, Helsinki, Finland, 4 Fujirebio Diagnostics AB, Elof Lindälvs gata 13, SE-414 58 Gothenburg, \\ Sweden, 5 Onson Consulting, Södra vägen 2, SE-412 54 Gothenburg, Sweden \\ * kapo.saukkonen@ @elsinki.fi
}

\section{Abstract}

\section{OPEn ACCess}

Citation: Saukkonen K, Hagström J, Mustonen H, Juuti A, Nordling S, Fermér C, et al. (2015)

Podocalyxin Is a Marker of Poor Prognosis in Pancreatic Ductal Adenocarcinoma. PLoS ONE 10(6): e0129012. doi:10.1371/journal.pone.0129012

Academic Editor: Francisco X. Real, Centro Nacional de Investigaciones Oncológicas (CNIO), SPAIN

Received: February 15, 2015

Accepted: April 21, 2015

Published: June 8, 2015

Copyright: @ 2015 Saukkonen et al. This is an open access article distributed under the terms of the Creative Commons Attribution License, which permits unrestricted use, distribution, and reproduction in any medium, provided the original author and source are credited.

Data Availability Statement: All relevant data are within the paper.

Funding: This study was supported by grants from Sigrid Juselius Foundation, Finska Läkaresällskapet, Liv och Hälsa, Kurt och Doris Palander Foundation and K Albin Johansson Foundation. Fujirebio Diagnostics $A B$ and Onson Consulting provided support in the form of salaries for authors $C F$ and $\mathrm{ON}$, but did not have any additional role in the study design, data collection and analysis, decision to publish, or preparation of the manuscript. The specific

\section{Aim of the Study}

Podocalyxin-like 1 is a transmembrane glyco-protein whose overexpression associates in many cancers with poor prognosis and unfavorable clinicopathological characteristics. Until now, its prognostic value has never been studied in pancreatic ductal adenocarcinoma (PDAC). The aim of this study was to investigate podocalyxin expression in PDAC by a novel monoclonal antibody and a commercially available polyclonal antibody.

\section{Patients and Materials}

With tissue microarrays and immuno-histochemistry, podocalyxin expression evaluation involved 168 PDAC patients. The associa-tions of the podocalyxin tumor expression with clinicopathological variables were explored by Fisher's exact test and the linear-by-linear test. Survival analyses were by Kaplan-Meier anal-ysis and the Cox proportional hazard model.

\section{Results}

The polyclonal antibody revealed membranous podocalyxin expression in $73(44.0 \%)$ specimens and the monoclonal antibody was highly expressed in $36(21.8 \%)$ cases. Membranous expression by the polyclonal antibody was associated with $T$ classification $(p=0.045)$ and perineural invasion $(p=0.005)$, and high expression by the mono-clonal antibody with poor differentiation $(p=0.033$ ). High podocalyxin expression associated significantly with higher risk of death from PDAC by both the polyclonal antibody (hazard ratio $(\mathrm{HR})=1.62$; 95\% confidence interval $(\mathrm{Cl}) 1.12-2.33 ; \mathrm{p}=0.01)$ and the monoclonal antibody $(\mathrm{HR}=2.10$, $95 \% \mathrm{Cl} 1.38-3.20 ; p<0.001)$. The results remained significant in multivariate analysis, adjusted for age, gender, stage, lymph node ratio $(\geq \mid<20 \%)$, and perivascular invasion (respectively as $\mathrm{HR}=2.03 ; 95 \% \mathrm{Cl} 1.32-3.13, \mathrm{p}=0.001$; and as $\mathrm{HR}=2.36 ; 95 \% \mathrm{Cl} 1.47-3.80$, $p<0.001)$. 
roles of these authors are articulated in the 'author contributions' section.

Competing Interests: The authors have declared that no competing interests exist.

\section{Conclusion}

We found podocalyxin to be an independent factor for poor prognosis in PDAC. To our knowledge, this is the first such report of its prognostic value.

\section{Introduction}

The prognosis of pancreatic ductal adenocarcinoma (PDAC) is extremely poor, with overall 5 -year survival less than 5\% [1,2]. Finland has about 1000 new cases per year, and PDAC is the third leading cause of cancer-related death [1]. In the United States, PDAC is the fourth leading cause of cancer-related mortality, causing annually about 40,000 deaths [2]. Despite improvements in management, the survival rate has not improved markedly over the last few decades [2]. At diagnosis, roughly $10 \%$ has localised disease and $25 \%$ regional disease [2]. Radical surgical resection is the only curative treatment, but disease is unresectable in about $80 \%$ of the cases [3]. Although overall survival is poor, there is a great variation between patients of the same stage, for whom new biomarkers might help in predicting prognosis. Research on potential biomarkers has been intense, but it still lacks good prognostic markers [4-6].

Podocalyxin-like 1 (PODXL), a transmembrane glycoprotein closely related to the hematopoietic stem cell marker CD34 and to endoglycan [7], regulates cell-to-cell adhesion through charge-repulsive effects but also contributes to cell morphology [7]. PODXL is normally expressed in hematopoietic progenitor cells [8], vascular endothelial cells [9], and renal podocytes [10]. First identified in the kidney, it helps there to maintain filtration pathways [11]. Loss of normal PODXL expression is associated with glomerulopathies-mainly with nephrotic syndrome [12].

PODXL overexpression has been described in several cancer types including leukemia and breast, colorectal, urothelial bladder, hepatocellular and prostate cancers [13-19]. In renal cell carcinoma, breast, and colorectal cancers, PODXL overexpression is an independent factor for poor outcome [14-16,20]. Whether PODXL is a marker of poor prognosis also in pancreatic cancer, remains unclear. It has been shown that PDAC cells are generally positive for PODXL, but other adenocarcinomas of the biliary and gastrointestinal tract are mainly negative [21]. Dallas et al. concluded that sialofucosylated PODXL is overexpressed by metastatic pancreatic cancer cells [22]. Furthermore, membranous PODXL expression has been suggested to correlate with poor prognosis in colorectal and urothelial bladder cancers [15-17]. Recently Kaprio et al. showed that high cytoplasmic expression of PODXL by a novel monoclonal antibody $(\mathrm{mAb})$ is a marker of poor prognosis in colorectal cancer [23].

In this study we examined the prognostic value of PODXL expression in PDAC, comparing PODXL expression by our in-house HES9 $\mathrm{mAb}$ with a commercially available polyclonal antibody (pAb).

\section{Materials and Methods}

\section{Patients}

The study population comprised 189 consecutive PDAC patients surgically treated in 20002011 at the Department of Surgery, Helsinki University Hospital. Median age at operation was 64 (range 39-84) years. There were 21 patients, who had received neoadjuvant chemotherapy. Those were excluded from the study. Survival data and cause of death of the patients were obtained from patients' records, Statistics Finland, and the Finnish Population Registry. This 
study complies with the declaration of Helsinki and was approved by the Surgical Ethics Committee of Helsinki University Central Hospital (Dnro HUS 226/E6/06, extension TMK02 \$66 17.4.2013) and the National Supervisory Authority of Welfare and Health gave the permission to use tissue samples without individual informed consent in this retrospective study (Valvira Dnro 10041/06.01.03.01/2012).

\section{Preparation of tumor tissue microarrays}

Formalin-fixed and paraffin-embedded surgical tissue samples were collected from the archives of the Department of Pathology, Helsinki University Hospital. Tissue specimens suitable for immunohistochemical evaluation were available from 168 patients. 15 patients were excluded due to inadequate or missing samples. All samples were re-evaluated by experienced pathologists (J.H. and S.N.) for confirmation of the histopathological diagnosis of PDAC. Most representative regions of tumor specimens were defined and tumor area was marked on hematoxylin- and eosin-stained tumor slides to prepare the TMA. Two 1.0-mm cores were taken from each tumor with a semiautomatic tissue microarrayer (Tissue Arrayer 1, Beecher Instruments Inc., Silver Spring, MD, USA).

\section{Antibodies}

The novel monoclonal in-house antibody (HES9) used in this study recognizes amino acid residues 189-192 of PODXL. The polyclonal antibody (HPA 2110, Atlas Antibodies, Stockholm, Sweden) recognizes amino acid residues $278-415$. The specificity of the polyclonal antibody has been validated by Western blotting and protein arrays, and PODXL protein expression mapped by immunohistochemistry in normal tissues and common cancers [24,25]. It has also served in other biomarker studies on colorectal, urothelial bladder and pancreatic cancer $[16,17,21]$.

The monoclonal antibody has been previously described in detail [23]. In brief, mice were immunized with the undifferentiated human embryonic (hES) stem cell line SA167 (Cellartis, Göteborg, Sweden, www.cellartis.com). All animal experiments were performed in accordance with the Animal Welfare Ordinance and the Animal Welfare Act of Sweden and approved by the Animal Experiments Ethics Committee of Gothenburg (approval no. 310-2005).

By conventional hybridoma technology, hybridoma cell lines were established producing mAbs against hES cells. Mimotope analysis, immunoprecipitation, and mass-spectrometry identified the target antigen as PODXL. The epitopes of both the monoclonal and the polyclonal antibody are in the extracellular portion of PODXL. Of four protein-coding PODXL splice variants, the epitope sequence of the pAb matches three at 100\% (PODXL 001, 005, and 201, The Human Protein Atlas). The fourth splice variant matches at 87\% (PODXL 202). The epitope sequence of the mAb HES9 matches all splice variants $100 \%$. [24,25]

\section{Immunohistochemistry}

Tumor-tissue microarray blocks were freshly cut into $4-\mu \mathrm{m}$ sections. After deparaffinization in xylene and rehydration through a gradually decreasing concentration of ethanol to distilled water, slides were treated in a PreTreatment module (Lab Vision Corp., Fremont, CA, USA) in Tris- $\mathrm{Hcl}\left(\mathrm{pH}\right.$ 8.5) buffer for $20 \mathrm{~min}$ at $98^{\circ} \mathrm{C}$ for antigen retrieval. Staining of sections was performed in an Autostainer 480 (Lab Vision Corp., Fremont, CA, USA) by the Dako REAL EnVision Detection system, Peroxidase/DAB+, Rabbit/Mouse (Dako, Glostrup, Denmark). Tissues were incubated with the $\mathrm{mAb}$ (dilution 1:800 $=8 \mu \mathrm{g} / \mathrm{ml}$ ) and with pAb (dilution 1:250 = 
$2.5 \mu \mathrm{g} / \mathrm{ml}$ ) for one hour at room temperature. A sample of colon tissue served as a positive control in each staining series.

\section{Evaluation of PODXL staining}

PODXL expression by the $\mathrm{mAb}$ was evenly distributed in the cytoplasm and was often granular. By the pAb, PODXL expression was also cytoplasmic with no expression in the nuclei. In many cases, a distinct membranous positivity emerged, even in cells with weak cytoplasmic positivity. Cytoplasmic staining was scored as negative (0), weakly positive (1), moderately positive (2) or strongly positive (3) according to staining intensity. For cases with distinct membranous staining by the $\mathrm{pAb}$, the score was recorded as 3 , regardless of cytoplasmic staining intensity. The highest score of the triplicates of each sample was considered representative for analysis. The stainings were scored by two independent investigators (K.S. and J.H.) without knowledge of clinical data and outcome. Differing scores required determination of a consensus score.

\section{Statistical analyses}

For statistical purposes, categories of PODXL expression were dichotomized for the $\mathrm{mAb}$ into low (0-2) and high (3) and for the pAb into non-membranous (0-2) and membranous (3). A categorization with three classes was created to study the two antibodies together: low ( $\mathrm{mAb}$, low and $\mathrm{pAb}$, non-membranous), moderate (either mAb, high or pAb, membranous), and high ( $\mathrm{mAb}$, high and $\mathrm{pAb}$, membranous). The Fischer exact-test or linear-by-linear association test served in evaluating associations between PODXL expression and relevant clinocopathological parameters. Survival analysis was done by the Kaplan-Meier method and compared by the log-rank test. The Bonferroni correction was used for multiple comparisons by dividing the probability level by the number of comparisons. The Cox regression proportional hazard model served for uni- and multivariate survival analysis adjusted for age, gender, stage, lymphnode ratio, and perivascular invasion. Interaction terms were considered, but with no significant interactions found. The Cox model assumption of constant hazard ratios over time was tested by including a time-dependent covariate separately for each testable variable at a time. The assumption was met with all variables. Variables with $\mathrm{p}<0.05$ in univariate analysis (age, gender, $T, N$, stage, lymph node ratio $(\geq /<20 \%)$, grade, perineural invasion, perivascular invasion, $\mathrm{mAb}, \mathrm{pAb}$ and combination of $\mathrm{mAb}$ and $\mathrm{pAb}$ ) were selected into the multivariate model, retaining age and sex in all models. To simplify the model, stage and lymph node ratio (LNR) were combined into a single variable. All tests were two-sided. A p-value of 0.05 or less was considered significant. All statistical analyses were with SPSS version 20.0 (IBM SPSS Statistics, version 20.0 for Windows; SPSS, Inc., Chicago, IL, USA, an IBM Company).

\section{Results}

\section{Immunohistochemical staining}

PODXL expression by the pAb was cytoplasmic in tumor cells, but in some cases, distinct membranous expression was visible, not correlating with intensity of cytoplasmic expression. Such a staining pattern was not apparent for the mAb: it was cytoplasmic and evenly distributed.

PODXL staining by the pAb could be evaluated in $166(98.8 \%)$ specimens: $13(7.8 \%)$ showing negative, 71 (42.8\%) weak, 55 (33.1\%) moderate, and 27 (16.3\%) strong staining (Fig 1).

PODXL staining by the mAb could be evaluated in 165 (98.2\%) specimens: 21 (12.7\%) showing negative, 69 (41.8\%) weak, 39 (23.6\%) moderate, and 36 (21.8\%) strong staining (Fig 2). 


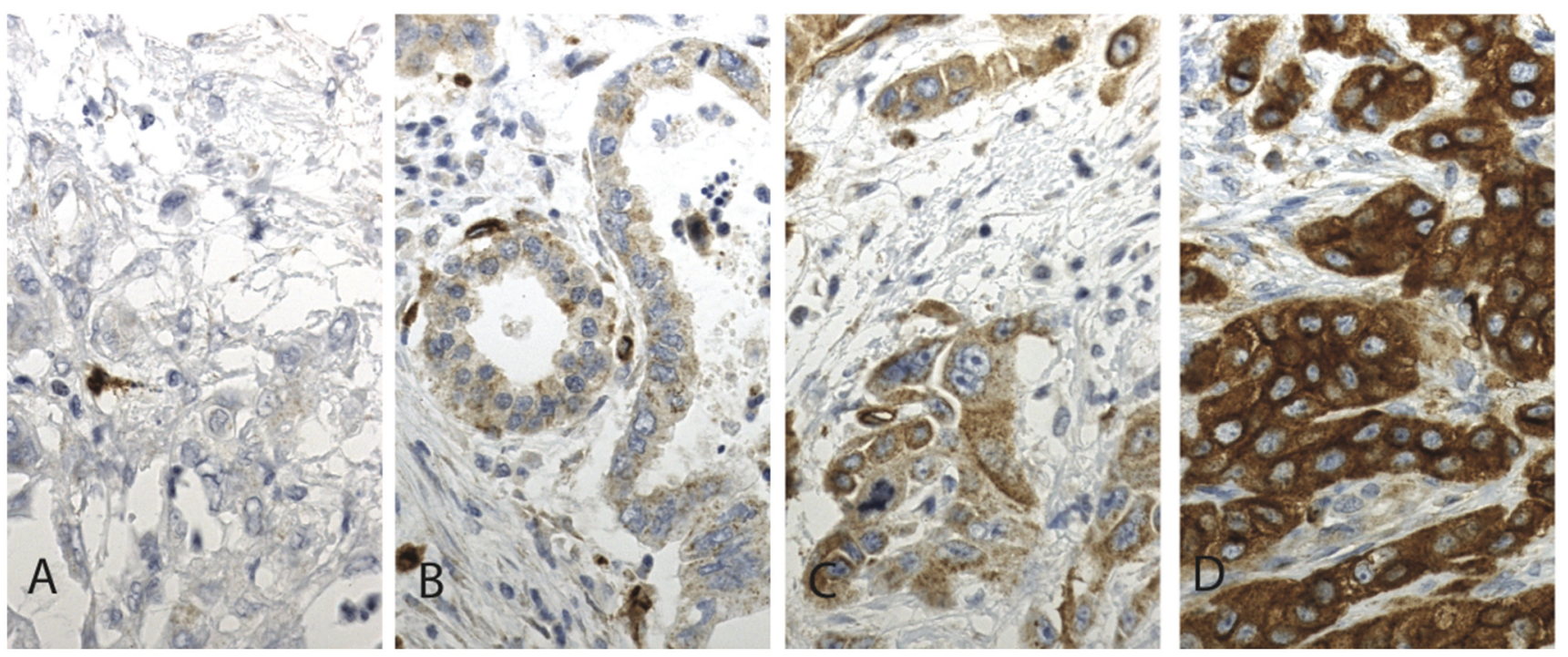

Fig 1. Immunohistochemical staining pattern of PODXL by polyclonal antibody HPA 2110 in pancreatic ductal adenocarcinoma. Representative images of PODXL expression in pancreatic ductal adenocarcinoma. (A) PODXL-negative, (B) weak cytoplasmic positivity, (C) moderate cytoplasmic positivity, and (D) strong and positive membranous positivity. Original magnification was $x 400$.

doi:10.1371/journal.pone.0129012.g001

\section{Association of PODXL expression with clinicopathological parameters separately and combined}

An association emerged between membranous PODXL expression by the $\mathrm{pAb}$ and $\mathrm{T}$ $(\mathrm{p}=0.045)$ and perineural invasion $(\mathrm{p}=0.005)$. High PODXL expression by the $\mathrm{mAb}$ was associated with poor differentiation $(\mathrm{p}=0.033)$. PODXL expression correlated neither with age, gender, stage, lymph-node ratio, tumor location (not shown), nor perivascular invasion (Tables 1 and 2).
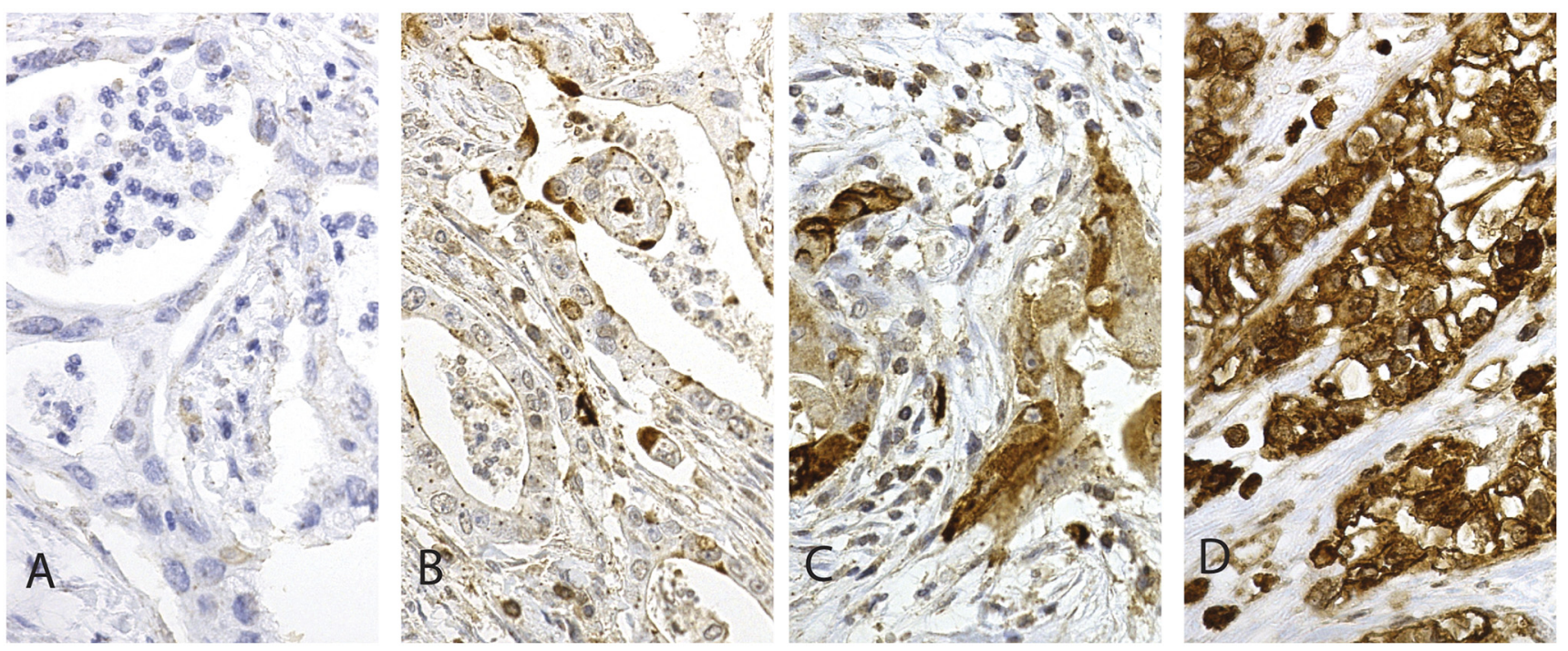

Fig 2. Immunohistochemical staining pattern of PODXL by monoclonal antibody HES9 in pancreatic ductal adenocarcinoma. Representative images of PODXL expression in pancreatic ductal adenocarcinoma. (A) PODXL-negative, (B) weak cytoplasmic positivity, (C) moderate cytoplasmic positivity, and (D) strong cytoplasmic positivity. Original magnification was $\times 400$.

doi:10.1371/journal.pone.0129012.g002 
Table 1. Association of clinicopathological parameters and PODXL expression by polyclonal antibody HPA 2110.

\begin{tabular}{|c|c|c|c|}
\hline$n(\%)$ & $\begin{array}{l}\text { Non-membranous } \\
93(56.0)\end{array}$ & $\begin{array}{l}\text { Membranous } \\
73(44.0)\end{array}$ & p-value \\
\hline \multicolumn{4}{|c|}{ Age, years } \\
\hline$<65$ & $46(49.5)$ & $36(49.3)$ & 1.000 \\
\hline$\geq 65$ & $47(50.5)$ & $37(50.7)$ & \\
\hline \multicolumn{4}{|l|}{ Gender } \\
\hline Male & $52(55.9)$ & $40(54.8)$ & 1.000 \\
\hline Female & $41(44.1)$ & $33(45.2)$ & \\
\hline \multicolumn{4}{|l|}{$\mathbf{T}$} \\
\hline 1 & $10(11.0)$ & $2(2.7)$ & 0.045 \\
\hline 2 & $25(27.5)$ & $18(24.7)$ & \\
\hline 3 & $54(59.3)$ & $50(68.5)$ & \\
\hline 4 & $2(2.2)$ & $3(4.1)$ & \\
\hline Missing & 2 & & \\
\hline \multicolumn{4}{|l|}{$\mathbf{N}$} \\
\hline 0 & $26(28.6)$ & $23(31.5)$ & 0.733 \\
\hline 1 & 65 (71.4) & $50(68.5)$ & \\
\hline Missing & 2 & & \\
\hline \multicolumn{4}{|l|}{ M } \\
\hline 0 & $88(95.7)$ & $69(95.8)$ & 1.000 \\
\hline 1 & $4(4.3)$ & $3(4.2)$ & \\
\hline Missing & 1 & 1 & \\
\hline \multicolumn{4}{|c|}{ Stage (WHO) } \\
\hline IA & $7(7.9)$ & $2(2.8)$ & 0.606 \\
\hline IB & $9(10.1)$ & $9(12.3)$ & \\
\hline IIA & $10(11.2)$ & $10(13.7)$ & \\
\hline IIB & $58(65.2)$ & $46(63.0)$ & \\
\hline III & $0(0.0)$ & $3(4.1)$ & \\
\hline IV & $5(5.6)$ & $3(4.1)$ & \\
\hline Missing & 4 & & \\
\hline \multicolumn{4}{|c|}{ Lymph node ratio } \\
\hline$<20 \%$ & $68(75.6)$ & $56(77.8)$ & 0.852 \\
\hline$\geq 20 \%$ & $22(24.4)$ & $16(22.2)$ & \\
\hline Missing & 3 & 1 & \\
\hline \multicolumn{4}{|l|}{ Grade } \\
\hline 1 & $17(21.2)$ & $7(11.1)$ & 0.103 \\
\hline 2 & $53(66.3)$ & $44(69.8)$ & \\
\hline 3 & $10(12.5)$ & $12(19.1)$ & \\
\hline Missing & 13 & 10 & \\
\hline \multicolumn{4}{|c|}{ Perineural invasion } \\
\hline Yes & $51(67.1)$ & $57(87.7)$ & 0.005 \\
\hline No & $25(22.9)$ & $8(12.3)$ & \\
\hline Missing & 17 & 8 & \\
\hline \multicolumn{4}{|c|}{ Perivascular invasion } \\
\hline Yes & $23(30.7)$ & $26(43.3)$ & 0.151 \\
\hline No & $52(69.3)$ & $34(56.7)$ & \\
\hline Missing & 18 & 13 & \\
\hline
\end{tabular}

Fischer exact-test was used for $2 \times 2$ tables and linear-by-linear association test for tables with more than two rows. Missing data excluded from the analyses.

doi:10.1371/journal.pone.0129012.t001 
Table 2. Association of clinicopathological parameters and PODXL expression by monoclonal antibody HES9.

\begin{tabular}{|c|c|c|c|}
\hline$n(\%)$ & $\begin{array}{l}\text { Low } \\
129 \text { (78.2) }\end{array}$ & $\begin{array}{l}\text { High } \\
36(21.8)\end{array}$ & p-value \\
\hline \multicolumn{4}{|c|}{ Age, years } \\
\hline$<65$ & $63(48.8)$ & $18(50.0)$ & 1.000 \\
\hline$\geq 65$ & $66(51.2)$ & $18(50.0)$ & \\
\hline \multicolumn{4}{|l|}{ Gender } \\
\hline Male & $73(56.6)$ & $18(50.0)$ & 0.570 \\
\hline Female & $56(43.4)$ & $18(50.0)$ & \\
\hline \multicolumn{4}{|l|}{$\mathbf{T}$} \\
\hline 1 & $10(7.9)$ & $2(5.7)$ & 0.776 \\
\hline 2 & $31(24.4)$ & $12(34.3)$ & \\
\hline 3 & $83(65.4)$ & $21(60.0)$ & \\
\hline 4 & $3(2.3)$ & $1(2.9)$ & \\
\hline Missing & 2 & 1 & \\
\hline \multicolumn{4}{|l|}{$\mathbf{N}$} \\
\hline 0 & $38(29.9)$ & $11(30.6)$ & 1.000 \\
\hline 1 & $89(70.1)$ & $25(69.4)$ & \\
\hline Missing & 2 & & \\
\hline \multicolumn{4}{|l|}{ M } \\
\hline 0 & 124 (96.9) & 33 (94.3) & 0.610 \\
\hline 1 & $4(3.1)$ & $2(5.7)$ & \\
\hline Missing & 1 & 1 & \\
\hline \multicolumn{4}{|c|}{ Stage (WHO) } \\
\hline IA & $7(5.6)$ & $2(5.6)$ & 0.531 \\
\hline IB & $15(12.0)$ & $3(8.3)$ & \\
\hline IIA & $16(12.8)$ & $4(11.1)$ & \\
\hline IIB & $80(64.0)$ & $24(66.6)$ & \\
\hline III & $2(1.6)$ & $1(2.8)$ & \\
\hline IV & $5(4.0)$ & $2(5.6)$ & \\
\hline Missing & 4 & & \\
\hline \multicolumn{4}{|c|}{ Lymph node ratio } \\
\hline$<20 \%$ & $96(76.8)$ & $27(75.0)$ & 0.826 \\
\hline$\geq 20 \%$ & $29(23.2)$ & $9(25.0)$ & \\
\hline Missing & 4 & & \\
\hline \multicolumn{4}{|l|}{ Grade } \\
\hline 1 & $20(18.2)$ & $4(12.5)$ & 0.033 \\
\hline 2 & $78(70.9)$ & $18(56.3)$ & \\
\hline 3 & $12(10.9)$ & $10(31.2)$ & \\
\hline Missing & 19 & 4 & \\
\hline \multicolumn{4}{|c|}{ Perineural invasion } \\
\hline Yes & $80(73.4)$ & $27(87.1)$ & 0.151 \\
\hline No & $29(26.6)$ & $4(12.9)$ & \\
\hline Missing & 20 & 5 & \\
\hline \multicolumn{4}{|c|}{ Perivascular invasion } \\
\hline Yes & $32(30.8)$ & $15(50.0)$ & 0.081 \\
\hline No & $72(69.2)$ & $15(50.0)$ & \\
\hline
\end{tabular}


Table 2. (Continued)

\begin{tabular}{llll}
\hline & Low & High & \\
$\mathbf{n}(\%)$ & $\mathbf{1 2 9}(\mathbf{7 8 . 2})$ & $\mathbf{3 6}(\mathbf{2 1 . 8 )}$ & p-value \\
\hline Missing & 25 & 6 & \\
\hline
\end{tabular}

Fischer exact-test was used for $2 \times 2$ tables and linear-by-linear association test for tables with more than two rows. Missing data excluded from the analyses.

doi:10.1371/journal.pone.0129012.t002

Analysis of combined PODXL expression with clinicopathological parameters showed significant associations between high PODXL expression and poor differentiation $(\mathrm{p}=0.014)$, perineural invasion $(\mathrm{p}=0.007)$ and perivascular invasion $(\mathrm{p}=0.039)$. High expression failed to correlate with age, gender, stage, or lymph node ratio (Table 3 ).

\section{Survival analysis}

For PDAC patients with membranous PODXL expression by the polyclonal antibody, cancerspecific survival (CSS) was significantly worse ( $\mathrm{p}=0.006$, Log-rank test); five-year CSS was 14.0\% (95\% CI 5.2-22.8\%) for patients with membranous PODXL expression compared to 24.8\% (95\% CI 15.0-34.6\%) for those with non-membranous expression (Fig 3).

PDAC patients with high PODXL expression by the monoclonal antibody showed a significantly poorer CSS than did those with low expression ( $\mathrm{p}=0.001)$; five-year CSS for PDAC patients with low expression was $24.8 \%$ (95\% CI 16.4-33.2\%) and for those with high expression, 4.4\% (95\% CI -3.6-12.4\%) (Fig 4).

A combination of $\mathrm{mAb}$ and $\mathrm{pAb}$ showed a significantly poorer CSS for PDAC patients with high expression than for those with low expression $(\mathrm{p}=0.001)$. No significant difference in CSS appeared, however, between patients with moderate and high expression $(\mathrm{p}=0.37)$, or between moderate and low expression ( $\mathrm{p}=0.020$, Bonferroni correction used). Five-year CSS for patients with low expression was $26.6 \%$ (95\% CI 16.2-37.0\%), with moderate expression $18.7 \%$ (95\% CI 6.5-30.9\%) and with high expression 5.0\% (95\% CI -4.2-14.2\%) (Fig 5).

Cox regression univariate analysis confirmed these results. High podocalyxin expression associated significantly with higher risk of death from PDAC by both the pAb (HR $=1.62 ; 95 \%$ CI 1.12-2.33; $\mathrm{p}=0.01)$ and the $\mathrm{mAb}(\mathrm{HR}=2.10,95 \% \mathrm{CI} 1.38-3.20 ; \mathrm{p}<0.001)$. The combined moderate expression of PODXL by both the $\mathrm{mAb}$ and $\mathrm{pAb}$ showed higher risk of death from PDAC ( $\mathrm{HR}=1.56,95 \% \mathrm{CI} 1.02-2.40 ; \mathrm{p}=0.042)$, and the risk was even higher with combined high expression $(\mathrm{HR}=2.21,95 \% \mathrm{CI} 1.39-3.54 ; \mathrm{p}<0.001)$. In multivariate analyses, adjusted for age, gender, stage, lymph-node ratio, and perivascular invasion, membranous PODXL expression by the $\mathrm{pAb}$ and high PODXL expression by the $\mathrm{mAb}$ remained statistically significant. The combined moderate and high expression of PODXL by both $\mathrm{mAb}$ and $\mathrm{pAb}$ also remained, by multivariate analysis, statistically significant (Table 4 ).

\section{Discussion}

We demonstrate that in PDAC tissue overexpression of PODXL is an independent predictor of poor prognosis, and that it associates with unfavorable clinicopathological factors. To our knowledge, this is the first report of the prognostic value of PODXL expression in PDAC.

PODXL expression has been demonstrated in PDAC earlier [21,22]. Ney et al reported that PODXL expression differentiates PDAC from adenocarcinomas occurring in the biliary tract [21]. In their study, $44 \%$ of the PDAC specimens were positive for PODXL. Dallas et al [22] showed immunopositivity for PODXL in $69 \%$ of the PDAC specimens. Staining intensity was 
Table 3. Association of clinicopathological parameters and PODXL expression by polyclonal antibody HPA 2110 and monoclonal antibody HES9 combined.

\begin{tabular}{|c|c|c|c|c|}
\hline n (\%) & $\begin{array}{l}\text { Low } \\
87(53.0)\end{array}$ & $\begin{array}{l}\text { Moderate } \\
45(27.4)\end{array}$ & $\begin{array}{l}\text { High } \\
32(19.6)\end{array}$ & p-value \\
\hline \multicolumn{5}{|c|}{ Age, years } \\
\hline$<65$ & $43(49.4)$ & $22(48.9)$ & $16(50.0)$ & 1.000 \\
\hline$\geq 65$ & $44(50.6)$ & $23(51.1)$ & $16(50.0)$ & \\
\hline \multicolumn{5}{|l|}{ Gender } \\
\hline Male & $50(57.5)$ & $24(53.3)$ & $17(53.1)$ & 0.689 \\
\hline Female & $37(42.5)$ & $21(46.7)$ & $15(46.9)$ & \\
\hline \multicolumn{5}{|l|}{$\mathbf{T}$} \\
\hline 1 & $10(11.7)$ & $0(0.0)$ & $2(6.3)$ & 0.227 \\
\hline 2 & $22(25.9)$ & $12(26.7)$ & $9(28.1)$ & \\
\hline 3 & $52(61.2)$ & $31(68.9)$ & $20(62.5)$ & \\
\hline 4 & $1(1.2)$ & $2(4.4)$ & $1(3.1)$ & \\
\hline Missing & 2 & & & \\
\hline \multicolumn{5}{|l|}{$\mathbf{N}$} \\
\hline 0 & $25(29.4)$ & $14(31.1)$ & $10(31.3)$ & 0.829 \\
\hline 1 & $60(70.6)$ & $31(68.9)$ & $22(68.7)$ & \\
\hline Missing & 2 & & & \\
\hline \multicolumn{5}{|l|}{$M$} \\
\hline 0 & $83(96.5)$ & $44(97.8)$ & $29(93.5)$ & 0.602 \\
\hline 1 & $3(3.5)$ & $1(2.2)$ & $2(6.5)$ & \\
\hline Missing & 1 & & 1 & \\
\hline \multicolumn{5}{|c|}{ Stage (WHO) } \\
\hline IA & $7(8.4)$ & $0(0.0)$ & $2(6.3)$ & 0.419 \\
\hline IB & $8(9.7)$ & $8(17.8)$ & $2(6.3)$ & \\
\hline$\| \mathrm{A}$ & $10(12.0)$ & $6(13.3)$ & $4(12.5)$ & \\
\hline IIB & $54(65.1)$ & $28(62.2)$ & $21(65.6)$ & \\
\hline III & $0(0.0)$ & $2(4.5)$ & $1(3.1)$ & \\
\hline IV & $4(4.8)$ & $1(2.2)$ & $2(6.3)$ & \\
\hline Missing & 4 & & & \\
\hline \multicolumn{5}{|c|}{ Lymph node ratio } \\
\hline$<20 \%$ & $63(75.0)$ & $35(79.5)$ & $24(75.0)$ & 0.907 \\
\hline$\geq 20 \%$ & $21(25.0)$ & $9(20.5)$ & $8(25.0)$ & \\
\hline Missing & 3 & 1 & & \\
\hline \multicolumn{5}{|l|}{ Gradus } \\
\hline 1 & $16(21.6)$ & $5(12.8)$ & $3(10.7)$ & 0.014 \\
\hline 2 & $51(68.9)$ & $28(71.8)$ & $17(60.7)$ & \\
\hline 3 & $7(9.5)$ & $6(15.4)$ & $8(28.6)$ & \\
\hline Missing & 13 & 6 & 4 & \\
\hline \multicolumn{5}{|c|}{ Perineural invasion } \\
\hline Yes & $48(67.6)$ & $32(75.0)$ & $26(92.9)$ & 0.007 \\
\hline No & $23(32.4)$ & $8(25.0)$ & $2(7.1)$ & \\
\hline Missing & 16 & 5 & 4 & \\
\hline \multicolumn{5}{|c|}{ Perivascular invasion } \\
\hline Yes & $19(27.1)$ & $15(41.7)$ & $13(48.1)$ & 0.039 \\
\hline No & $51(72.9)$ & $21(58.3)$ & $14(51.9)$ & \\
\hline Missing & 17 & 9 & 5 & \\
\hline
\end{tabular}

Linear-by-linear association test was used for this table. Missing data excluded from the analyses.

doi:10.1371/journal.pone.0129012.t003 


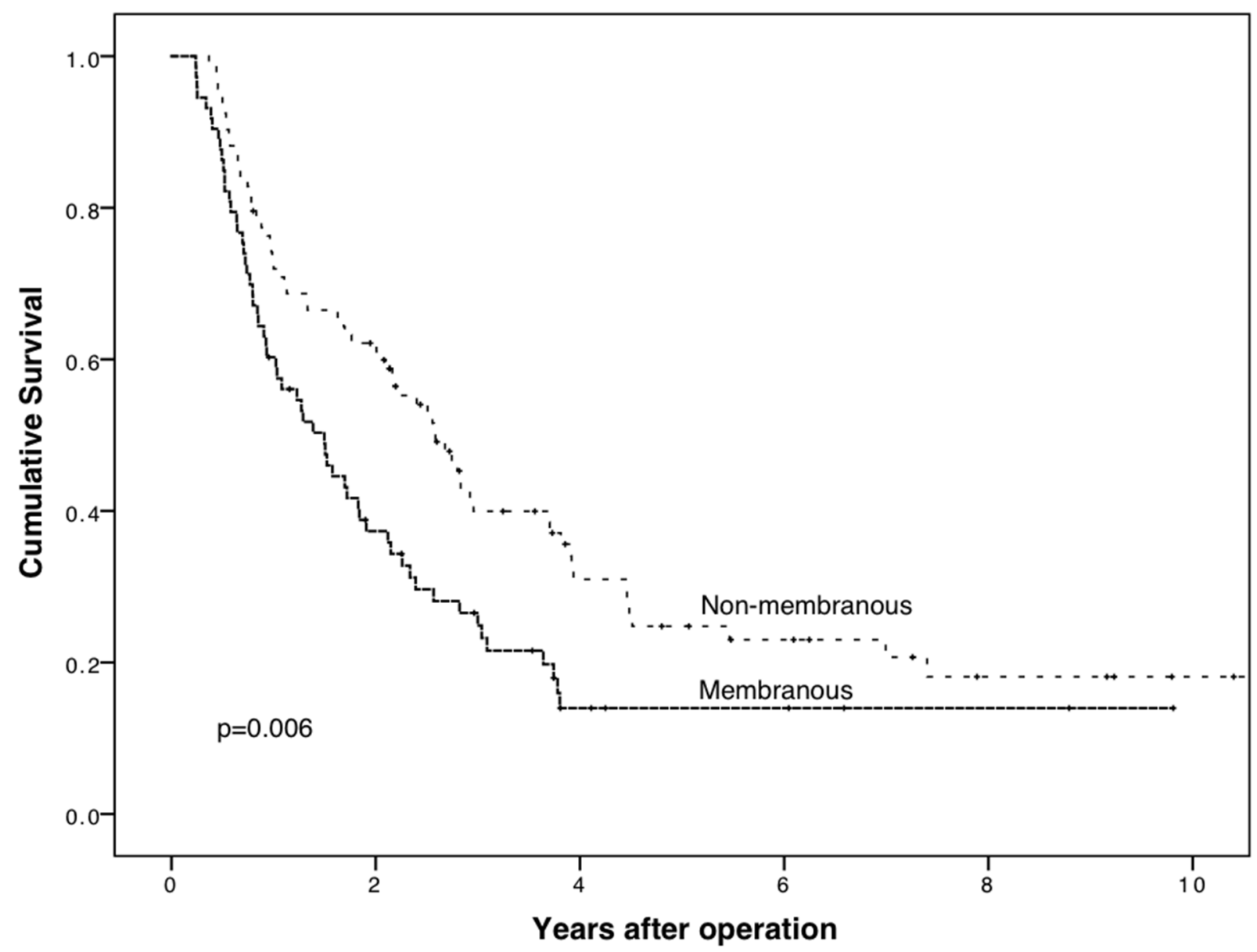

Fig 3. Membranous PODXL expression by polyclonal antibody HPA 2110 is a marker of poor prognosis in pancreatic ductal adenocarcinoma. Cancer-specific survival analysis according to the Kaplan-Meier method for membranous PODXL expression by the polyclonal antibody HPA 2110 in pancreatic ductal adenocarcinoma. Log-rank test was used here.

doi:10.1371/journal.pone.0129012.g003 


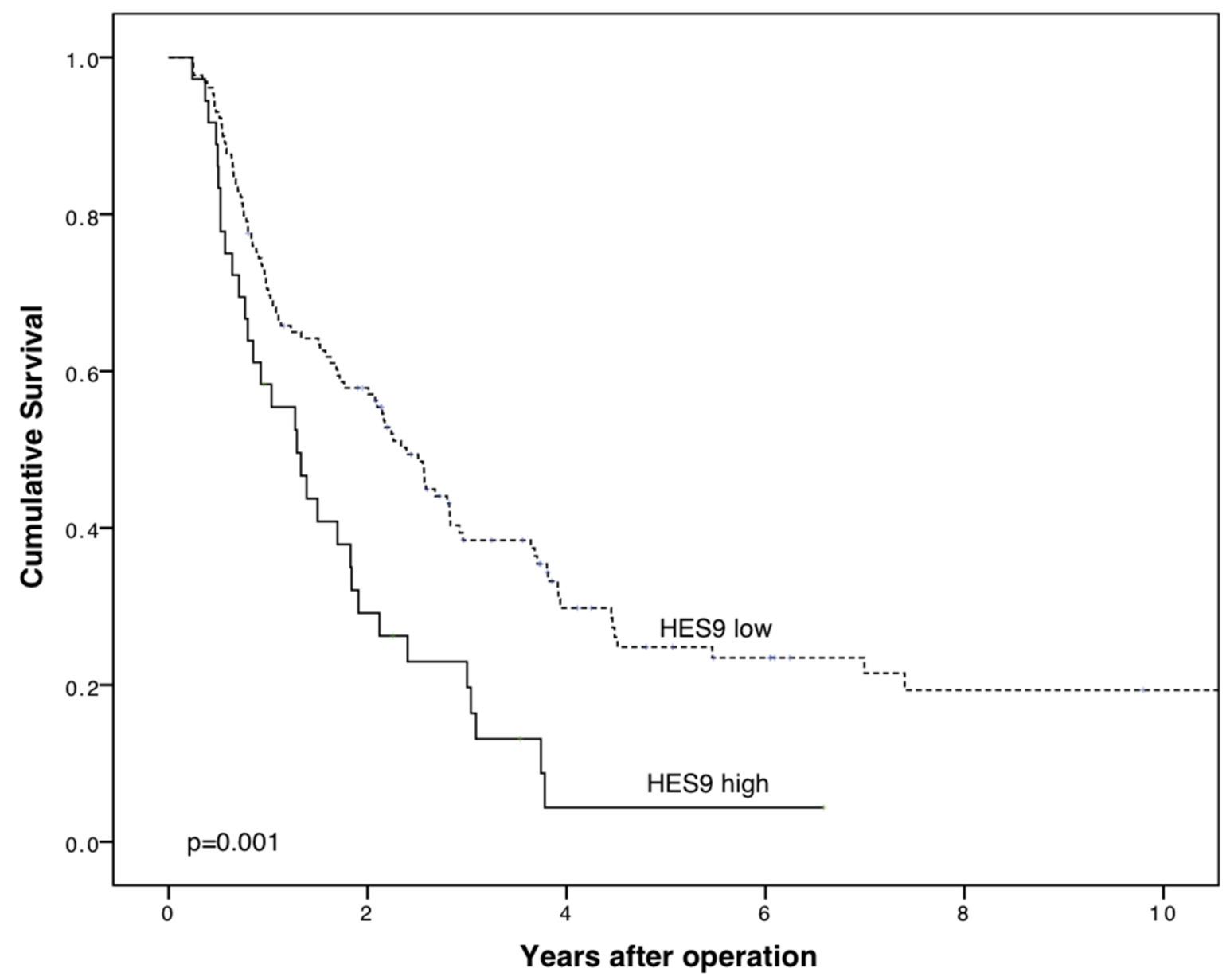

Fig 4. High PODXL expression by monoclonal antibody HES9 is a marker of poor prognosis in pancreatic ductal adenocarcinoma. Cancer-specific survival analysis according to the Kaplan-Meier method for high PODXL expression by the monoclonal antibody HES9 in pancreatic ductal adenocarcinoma. Log-rank test was used here. MAb HES9 recognizes PODXL protein.

doi:10.1371/journal.pone.0129012.g004 


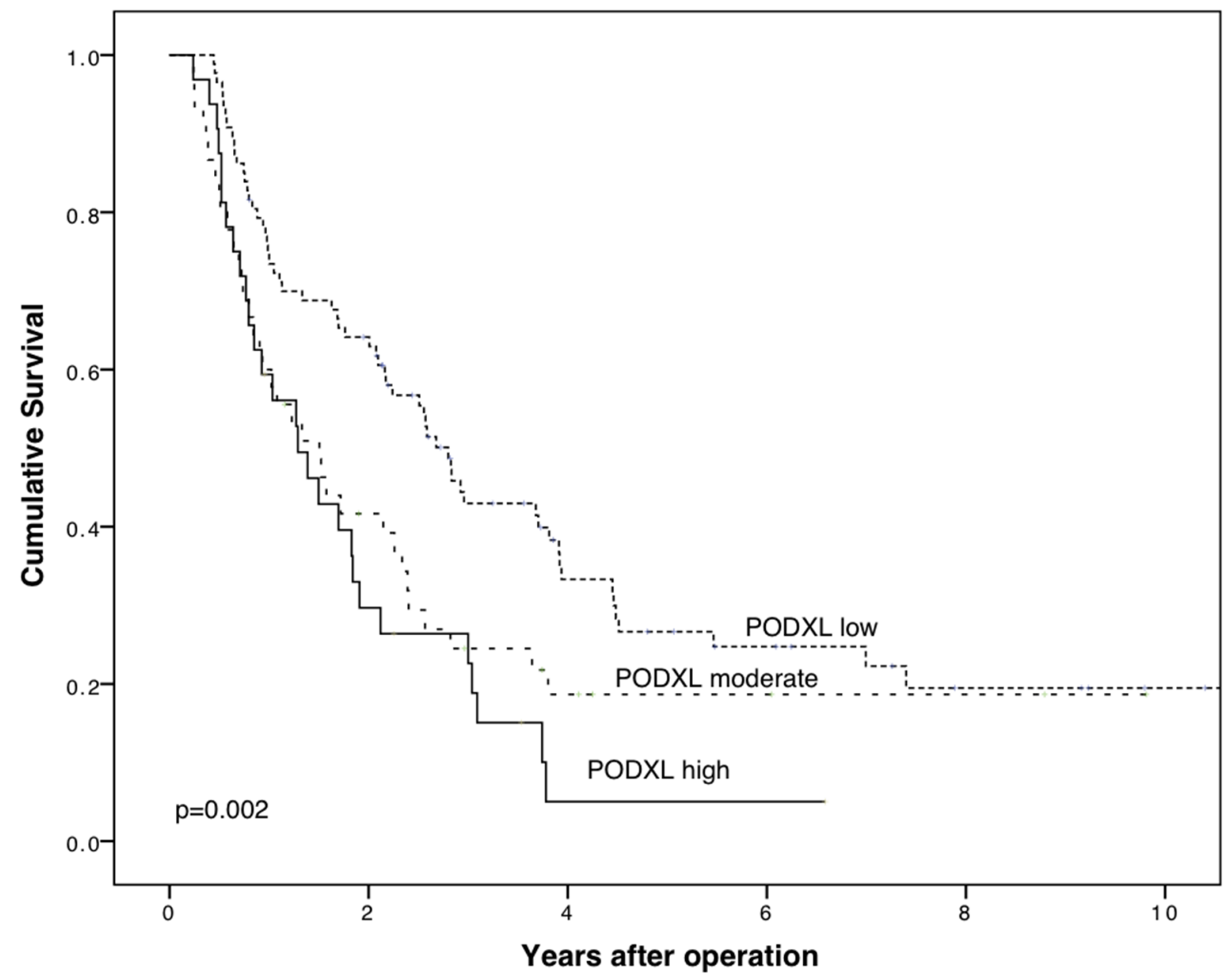

Fig 5. Concomitant positivity by two PODXL antibodies. Cancer-specific survival analysis according to the Kaplan-Meier method for combined expression of PODXL by the polyclonal antibody HPA 2110 and the monoclonal antibody HES9. A categorization with three classes was created to study the two antibodies together: low (mAb, low and pAb, non-membranous), moderate (either mAb, high or pAb, membranous), and high (mAb, high and pAb, membranous).

doi:10.1371/journal.pone.0129012.g005

independent prognostic factor in multivariate analysis independent of the antibody. Scoring was easier and staining differences were clearer by the mAb than by the pAb. Five-year CSS was lower for patients with high PODXL expression by the mAb than for patients with membranous PODXL expression by the pAb (4.4\% vs. 14.0\%). This supports the role of cytoplasmic overexpression of PODXL as a marker of poor prognosis.

The strength of this study is a well-characterized, consecutive, and quite large patient cohort with PDAC. Clinical follow-up and survival data were reliable and up-to-date. All histological samples were re-evaluated by experienced pathologists; other types of pancreatic cancer other than ductal adenocarcinoma were excluded. By the TMA technique, only a small area of each tumor is evaluated and thus the staining result may not be representative. We tried to diminish this possible error by taking cores from different parts of the tumor and altogether scored six different spots for each tumor. Only a small proportion (1.2-1.8\%) of our TMA spots were lost due to technical reasons. 
Table 4. Cox uni- and multivariate analysis of relative risk of death from pancreatic ductal adenocarcinoma by PODXL expression.

\begin{tabular}{|c|c|c|c|c|c|c|c|c|}
\hline \multicolumn{3}{|c|}{ Polyclonal antibody } & \multicolumn{3}{|c|}{ Monoclonal antibody } & \multicolumn{3}{|c|}{ Combined } \\
\hline PODXL expression & HR $(95 \% \mathrm{Cl})$ & P-value & PODXL expression & HR (95\% Cl) & P-value & PODXL expression & (HR 95\% Cl) & P-value \\
\hline & Univariate & & & Univariate & & & Univariate & \\
\hline Non-membranous & 1.00 & & Low & 1.00 & & Low & 1.00 & \\
\hline \multirow[t]{3}{*}{ Membranous } & $1.62(1.12-2.33)$ & 0.01 & High & $2.10(1.38-3.20)$ & $<0.001$ & Moderate & $1.56(1.02-2.40)$ & 0.042 \\
\hline & & & & & & High & $2.21(1.39-3.54)$ & $<0.001$ \\
\hline & Multivariate & & & Multivariate & & & Multivariate & \\
\hline Non-membranous & 1.00 & & Low & 1.00 & & Low & 1.00 & \\
\hline \multirow[t]{2}{*}{ Membranous } & $2.03(1.32-3.13)$ & 0.001 & High & $2.36(1.47-3.80)$ & $<0.001$ & Moderate & $2.07(1.25-3.44)$ & 0.005 \\
\hline & & & & & & High & $2.67(1.55-4.59)$ & $<0.001$ \\
\hline
\end{tabular}

Abbrevations $\mathrm{Cl}=$ Confidence interval, $\mathrm{HR}=$ Hazard ratio. Multivariate analysis included adjustment for age, gender, stage (IA-IIA, IIB and III), lymph node ratio $(\geq 1<20 \%)$, and perivascular invasion.

doi:10.1371/journal.pone.0129012.t004

\section{Conclusion}

To our knowledge, this is the first report to show that PODXL is an independent marker of poor prognosis in PDAC. Both membranous expression of PODXL by a polyclonal antibody (HPA 2110) and high cytoplasmic expression of PODXL by a monoclonal antibody (HES9) defined groups with poor prognosis. To clarify the different expression patterns of the two antibodies, we can speculate that they can either recognize different variants of PODXL in PDAC or identify PODXL at different form in the cytoplasm or cellular membrane.

\section{Acknowledgments}

We thank Päivi Peltokangas and Elina Aspiala for their technical assistance.

\section{Author Contributions}

Conceived and designed the experiments: $\mathrm{CH}$. Performed the experiments: KS JH. Analyzed the data: KS HM. Contributed reagents/materials/analysis tools: KS JH HM AJ SN CF ON HS. Wrote the paper: KS JH HM SN HS CH. Provided the antibody HES9: CF ON.

\section{References}

1. Finnish cancer registry. (2014) Cancer statistics. Available: www.cancerregistry.fi.

2. Siegel R, Ma J, Zou Z, Jemal A. (2014) Cancer statistics, 2014. CA Cancer J Clin 64: 9-29. doi: 10. 3322/caac.21208 PMID: 24399786

3. Li D, Xie K, Wolff R, Abbruzzese JL. (2004) Pancreatic cancer. Lancet 363: 1049-1057. PMID: 15051286

4. Ansari D, Rosendahl A, Elebro J, Andersson R. (2011) Systematic review of immunohistochemical biomarkers to identify prognostic subgroups of patients with pancreatic cancer. Br J Surg 98: 1041-1055. doi: 10.1002/bjs.7574 PMID: 21644238

5. Jamieson NB, Carter CR, McKay CJ, Oien KA. (2011) Tissue biomarkers for prognosis in pancreatic ductal adenocarcinoma: A systematic review and meta-analysis. Clin Cancer Res 17: 3316-3331. doi: 10.1158/1078-0432.CCR-10-3284 PMID: 21444679

6. Fong ZV, Winter JM. (2012) Biomarkers in pancreatic cancer: Diagnostic, prognostic, and predictive. Cancer J 18: 530-538. doi: 10.1097/PPO.0b013e31827654ea PMID: 23187839 
7. Nielsen JS, McNagny KM. (2009) The role of podocalyxin in health and disease. J Am Soc Nephrol 20: 1669-1676. doi: 10.1681/ASN.2008070782 PMID: 19578008

8. Doyonnas R, Nielsen JS, Chelliah S, Drew E, Hara T, et al. (2005) Podocalyxin is a CD34-related marker of murine hematopoietic stem cells and embryonic erythroid cells. Blood 105: 4170-4178. PMID: 15701716

9. Horvat R, Hovorka A, Dekan G, Poczewski H, Kerjaschki D. (1986) Endothelial cell membranes contain podocalyxin - the major sialoprotein of visceral glomerular epithelial cells. J Cell Biol 102: 484-491. PMID: 3511072

10. Kerjaschki D, Noronha-Blob L, Sacktor B, Farquhar MG. (1984) Microdomains of distinctive glycoprotein composition in the kidney proximal tubule brush border. J Cell Biol 98: 1505-1513. PMID: 6371023

11. Takeda T, Go WY, Orlando RA, Farquhar MG. (2000) Expression of podocalyxin inhibits cell-cell adhesion and modifies junctional properties in madin-darby canine kidney cells. Mol Biol Cell 11:3219-3232. PMID: 10982412

12. Kavoura E, Gakiopoulou H, Paraskevakou H, Marinaki S, Agrogiannis G, Stofas A, et al. (2011) Immunohistochemical evaluation of podocalyxin expression in glomerulopathies associated with nephrotic syndrome. Hum Pathol 42: 227-235. doi: 10.1016/j.humpath.2010.05.028 PMID: 21106221

13. Kelley TW, Huntsman D, McNagny KM, Roskelley CD, Hsi ED. (2005) Podocalyxin: A marker of blasts in acute leukemia. Am J Clin Pathol 124: 134-142. PMID: 15923169

14. Somasiri A, Nielsen JS, Makretsov N, McCoy ML, Prentice L, Gilks CB, et al. (2004) Overexpression of the anti-adhesin podocalyxin is an independent predictor of breast cancer progression. Cancer Res 64: 5068-5073. PMID: 15289306

15. Larsson A, Johansson ME, Wangefjord S, Gaber A, Nodin B, Kucharzewska P, et al. (2011) Overexpression of podocalyxin-like protein is an independent factor of poor prognosis in colorectal cancer. $\mathrm{Br}$ J Cancer 105: 666-672. doi: 10.1038/bjc.2011.295 PMID: 21829192

16. Larsson A, Fridberg M, Gaber A, Nodin B, Leveen P, Jönsson G, et al. (2012) Validation of podocalyxinlike protein as a biomarker of poor prognosis in colorectal cancer. BMC Cancer 12: 282-2407-12-282. doi: 10.1186/1471-2407-12-282 PMID: 22769594

17. Boman K, Larsson AH, Segersten U, Kuteeva E, Johannesson H, Nodin B, et al. (2013) Membranous expression of podocalyxin-like protein is an independent factor of poor prognosis in urothelial bladder cancer. Br J Cancer 108: 2321-2328. doi: 10.1038/bjc.2013.215 PMID: 23652315

18. Heukamp LC, Fischer HP, Schirmacher P, Chen X, Breuhahn K, Nicolay C, et al. (2006) Podocalyxin-like protein 1 expression in primary hepatic tumours and tumour-like lesions. Histopathology 49: 242-247. PMID: 16918970

19. Casey G, Neville PJ, Liu X, Plummer SJ, Cicek MS, Krumroy LM, et al. (2006) Podocalyxin variants and risk of prostate cancer and tumor aggressiveness. Hum Mol Genet 15: 735-741. PMID: 16434482

20. Hsu YH, Lin WL, Hou YT, Pu YS, Shun CT, Chen CL, et al. (2010) Podocalyxin EBP50 ezrin molecular complex enhances the metastatic potential of renal cell carcinoma through recruiting Rac1 guanine nucleotide exchange factor ARHGEF7. Am J Pathol 176: 3050-3061. doi: 10.2353/ajpath.2010.090539 PMID: 20395446

21. Ney JT, Zhou H, Sipos B, Buttner R, Chen X, Klöppel G, et al. (2007) Podocalyxin-like protein 1 expression is useful to differentiate pancreatic ductal adenocarcinomas from adenocarcinomas of the biliary and gastrointestinal tracts. Hum Pathol 38: 359-364. PMID: 17137615

22. Dallas MR, Chen SH, Streppel MM, Sharma S, Maitra A, Konstantopoulos K. (2012) Sialofucosylated podocalyxin is a functional $\mathrm{E}$ - and L-selectin ligand expressed by metastatic pancreatic cancer cells. Am J Physiol Cell Physiol 303: C616-C624. doi: 10.1152/ajpcell.00149.2012 PMID: 22814396

23. Kaprio T, Fermer C, Hagstrom J, Mustonen H, Bockelman C, Nilsson O, et al. (2014) Podocalyxin is a marker of poor prognosis in colorectal cancer. BMC Cancer 14: 493-2407-14-493. doi: 10.1186/ 1471-2407-14-493 PMID: 25004863

24. Uhlen M, Bjorling E, Agaton C, Szigyarto CA, Amini B, Andersen E, et al. (2005) A human protein atlas for normal and cancer tissues based on antibody proteomics. Mol Cell Proteomics 4: 1920-1932. PMID: 16127175

25. Ponten F, Jirstrom K, Uhlen M. (2008) The human protein atlas-a tool for pathology. J Pathol 216: 387-393. doi: 10.1002/path.2440 PMID: 18853439

26. Kaprio T, Hagstrom J, Fermer C, Mustonen H, Bockelman C, Nilsson O, et al. (2014) A comparative study of two PODXL antibodies in 840 colorectal cancer patients. BMC Cancer 14: 494-2407-14-494. doi: 10.1186/1471-2407-14-494 PMID: 25004935 
27. Cipollone JA, Graves ML, Kobel M, Kalloger SE, Poon T, Gilks CB, et al. (2012) The anti-adhesive mucin podocalyxin may help initiate the transperitoneal metastasis of high grade serous ovarian carcinoma. Clin Exp Metastasis 29: 239-252. doi: 10.1007/s10585-011-9446-0 PMID: 22262060

28. Nielsen JS, Graves ML, Chelliah S, Vogl AW, Roskelley CD, McNagny KM. (2007) The CD34-related molecule podocalyxin is a potent inducer of microvillus formation. PLoS One 2: e237. doi: 10.1371/ journal.pone.0000237 PMID: 17311105 